\title{
Pathophysiology of valvular heart disease (Review)
}

\author{
YI ZENG ${ }^{1}$, RONGRONG SUN ${ }^{1}$, XIANCHI LI ${ }^{2}$, MIN LIU ${ }^{3}$, SHUANG CHEN $^{2}$ and PEIYING ZHANG ${ }^{2}$ \\ ${ }^{1}$ Xuzhou Clinical Medical College of Nanjing University of Chinese Medicine; ${ }^{2}$ Department of Cardiology, \\ Xuzhou Central Hospital, The Affiliated Xuzhou Hospital of Medical College of Southeast University; \\ ${ }^{3}$ Department of Cardiology, Xuzhou Clinical School of Xuzhou Medical College, Xuzhou, Jiangsu 221009, P.R. China
}

Received November 9, 2015; Accepted February 5, 2016

DOI: $10.3892 /$ etm. 2016.3048

\begin{abstract}
Valvular heart disease (VHD) is caused by either damage or defect in one of the four heart valves, aortic, mitral, tricuspid or pulmonary. Defects in these valves can be congenital or acquired. Age, gender, tobacco use, hypercholesterolemia, hypertension, and type II diabetes contribute to the risk of disease. VHD is an escalating health issue with a prevalence of $2.5 \%$ in the United States alone. Considering the likely increase of the aging population worldwide, the incidence of acquired VHD is expected to increase. Technological advances are instrumental in identifying congenital heart defects in infants, thereby adding to the growing VHD population. Almost one-third of elderly individuals have echocardiographic or radiological evidence of calcific aortic valve (CAV) sclerosis, an early and subclinical form of CAV disease (CAVD). Of individuals ages $>60$, $\sim 2 \%$ suffer from disease progression to its most severe form, calcific aortic stenosis. Surgical intervention is therefore required in these patients as no effective pharmacotherapies exist. Valvular calcium load and valve biomineralization are orchestrated by the concerted action of diverse cell-dependent mechanisms. Signaling pathways important in skeletal morphogenesis are also involved in the regulation of cardiac valve morphogenesis, CAVD and the pathobiology of cardiovascular calcification. CAVD usually occurs without any obvious symptoms in early stages over a long period of time and symptoms are identified at advanced stages of the disease, leading to a high rate of mortality. Aortic valve replacement is the only primary treatment of choice. Biomarkers such as asymmetric dimethylarginine, fetuin-A, calcium phosphate product, natriuretic peptides and osteopontin have been useful in improving outcomes among various disease states. This
\end{abstract}

Correspondence to: Dr Peiying Zhang, Department of Cardiology, Xuzhou Central Hospital, The Affiliated Xuzhou Hospital of Medical College of Southeast University, 199 South Jiefang Road, Xuzhou, Jiangsu 221009, P.R. China

E-mail: zpying58@126.com

Key words: valvular heart disease, calcific aortic valve disease, aortic valve stenosis, congenital heart disease, endothelial cells, biomineralization, calcification review, highlights the current understanding of the biology of VHD, with particular reference to molecular and cellular aspects of its regulation. Current clinical questions and the development of new strategies to treat various forms of VHD medically were addressed.

\section{Contents}

1. Introduction

2. Structure of cardiac valve and pathogenesis of CAVD

3. Histopathology of CAVD

4. Inflammation and activation of CAVD pathogenesis

5. Genetics of CAVD

6. Treatment choices and biomarkers

\section{Introduction}

Valvular heart disease (VHD) is a major health problem afflicting the elderly in particular, with a prevalence of $2.5 \%$ in the United States. VHD occurs due to congenital defects or because of acquired pathology (1). Calcific aortic valve disease (CAVD) is initiated as aortic valve sclerosis (AVSc), which is a mild thickening of the valve, to aortic valve stenosis (AVS), which results in severe impairment of the valve motion. CAVD is increasingly present in the aging population, reaching epidemic proportions, with approximately one third of individuals aged $>65$ years, showing sub-clinical evidence of CAVD, in the form of aortic sclerosis (2). As a large proportion of the worldwide population is becoming aged, the prevalence of acquired forms of VHD is expected to rise (3). Age, gender, tobacco use, hypercholesterolemia, rheumatic heart disease and hypertension constitute significant risk factors of acquired CAVD. Congenital CAVD primarily results from the disturbed expression of genes that are involved in normal heart valve development. Congenital valve abnormalities comprise almost $50 \%$ of the cases of congenital heart defects (CHD) (4). Advances in the identification of these defects and in the associated care for infants suffering from CHDs is on the rise, thus increasing the net incidence and burden of congenital valve diseases (4). Type II diabetes is considered an important risk factor for native CAVD (5). The pathogenesis of congenital and acquired CAVD is likely due to the interplay of genetic and environmental influences, even though the precise mechanisms are not known. 


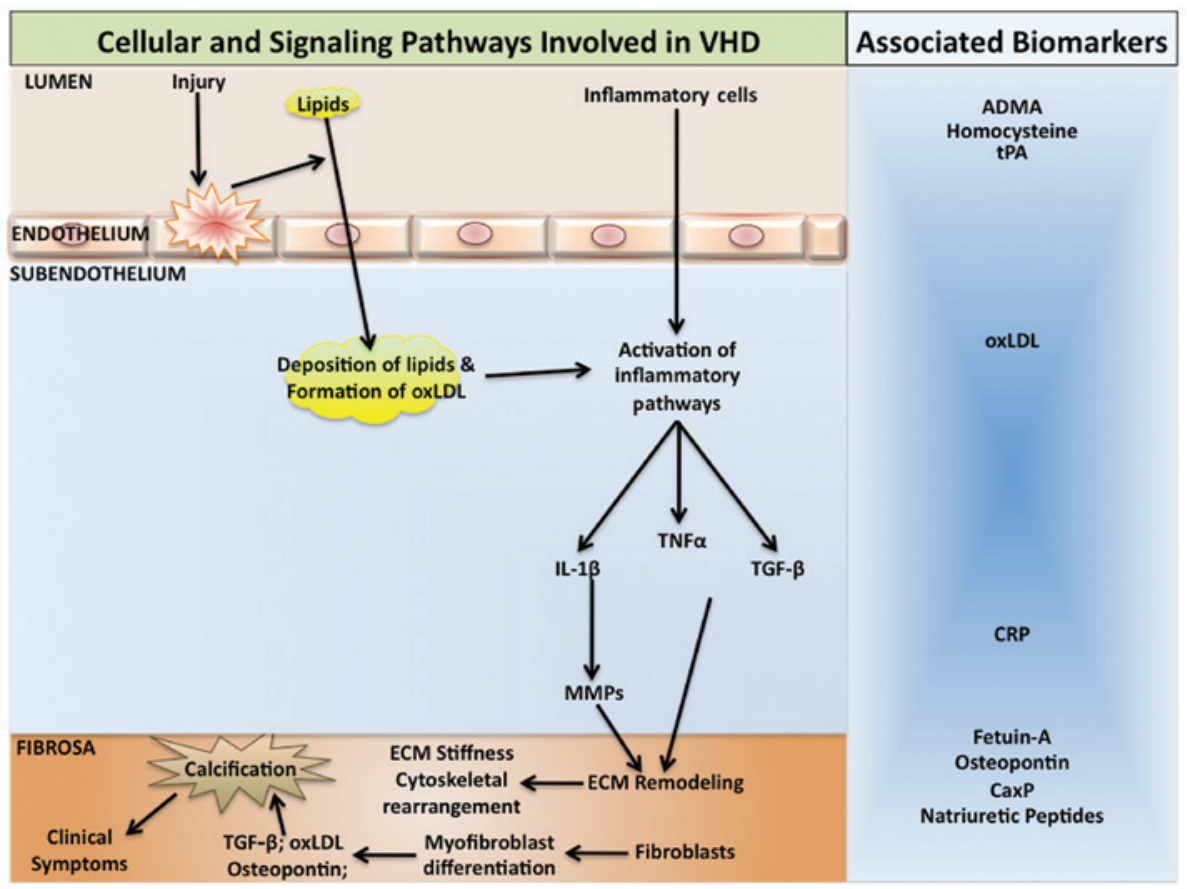

Figure 1. Pathogenic pathways involved in calcific aortic valve disease. Mechanical stress or injury on the aortic valve along with other atherosclerotic risk factors causes valvular endothelial dysfunction. This leads to lipid deposition in the subendothelium where they are oxidized and factors such as oxidized low-density lipoprotein (oxLDL) are formed. Inflammatory cells such as monocytes, infiltrate the valve tissue and form foam cells by phagocytosis of the lipids. Inflammatory cytokines are released which promote remodeling of the extracellular matrix. Fibroblasts transdifferentiate into valvular myofibroblasts with an osteoblast-like phenotype, and cause calcification. Biomarkers are associated with different stages of CAVD and can be useful in following the pathogenesis of the disease. TNF $\alpha$, tumor necrosis factor $\alpha$; TGF- $\beta$, transforming growth factor- $\beta$; IL- $1 \beta$, interleukin- $1 \beta$; MMP, matrix metalloproteases; ECM, extracellular matrix; ADMA, asymmetric dimethylaminoarginine; tPA, tissue plasminogen activator; CRP, C-reactive protein; CaxP, calcium phosphate product.

Although the incidence of VHD is high, therapeutic approaches for this disease are limited. The only available primary clinical approach for valve repair or replacement is surgery as the primary treatment $(6,7)$. In fact, aortic valve replacement is the second most frequent cardiac surgery following coronary artery bypass grafting (8). CAVD advances to calcific aortic stenosis (CAS), which is the most severe form of the disease. It is extremely debilitating affecting as many as $2 \%$ of individuals $>60$ years of age, requiring surgery to preclude death, once the symptoms become evident (9). CAVD is mainly diagnosed by clinical examination, echocardiography and cardiac catheterization. There are also many potential biomarkers that provide clinically useful information regarding the extent, severity, progression and prognosis of CAVD (8).

\section{Structure of cardiac valve and pathogenesis of CAVD}

The atrioventricular valves (mitral and tricuspid) and the semilunar valves (aortic and pulmonic) are two types of mature heart valves. These valves consist of an outer layer of valve endothelial cells (VECs) surrounding three layers of extracellular matrix each with specialized function and interspersed with valve interstitial cells (VICs) (10). Changes in the functionality and localization of matrix components potentially lead to VHD, since the proper organization of extracellular matrix (ECM) is essential in maintaining overall valve morphology and normal valve function. The three layers of ECM, consisting of collagens, proteoglycans and elastin, collectively contribute to the biomechanical support for the valves and any derangements in these morphological units can have detrimental effects on the complicated structures of valves that open and close approximately 100,000 times daily in order to maintain proper directionality of blood flow through the heart chambers (11). The protective endothelium over the surface of the valve leaflets is formed by the VECs, which communicate with VICs in the underlying layer and regulate their response to alterations in the blood flow (10). Genetic or acquired/environmental causes that disrupt the normal organization and composition of the ECM and communication between VECs and VICs alter valve mechanics and interfere with the valve leaflet function, culminating in heart failure (11).

\section{Histopathology of CAVD}

The histopathologic heterogeneity of CAVD indicates the involvement of diverse cell-dependent mechanisms that regulate calcium load on the valve leaflets (12), as well as the participation of different cell types, including interstitial cells, endothelial cells and cardiac chondrocytes, in valve biomineralization (13) (Fig. 1). Histopathologic studies (12) demonstrated the presence of calcified nodules composed of amorphous calcium phosphate, without any organization into specific histological structures. In these affected valves, similar to atherosclerosis, there are signs of inflammation and bone morphogenetic protein-2 expression (12). Additionally, woven and lamellar bone with osteoblast matrix production and vascularization has been identified in calcifying native aortic valves (14). During the pathogenesis of CAVD, one of 


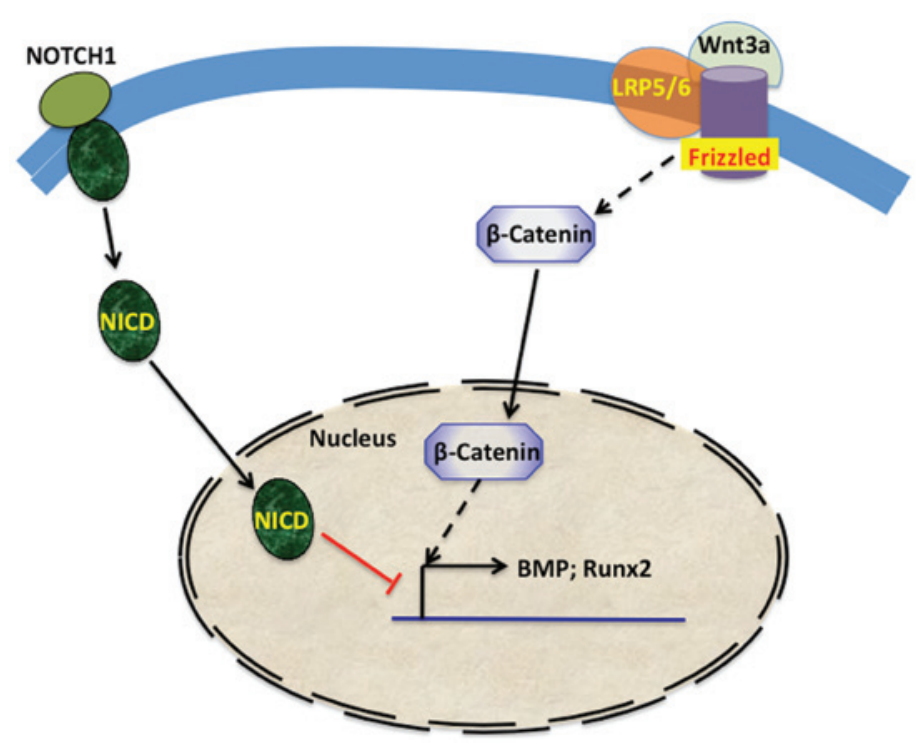

Figure 2. Crosstalk between the Notch and Wnt signaling pathways in calcific aortic valve disease. Notch 1 signaling, which represses BMP2 and Runx2 expression and impedes $\beta$-catenin stabilization and signaling, is useful in the prevention of valvular calcification. In calcific aortic valve disease, elevated levels of Wnt 3 a activate the coreceptor complex formed by Frizzled and Lrp5/6, leading to the stabilization of $\beta$-catenin and promoting the osteogenic transition of valve interstitial cells and valvular calcification. BMP, bone morphogenetic protein; NICD, Notch intracellular domain; Runx2, runt-related transcription factor 2.

the earliest events following endothelial cell dysfunction is the accumulation of lipids and subendothelial matrix at the ventricular surface of the valve with downward displacement of the subjacent elastic lamina while plaque-like subendothelial deposits occur on the aortic surface of the valve. It has been suggested that VECs via the endothelial-mesenchymal transition (EMT), can contribute to calcifying vascular cell types, in response to stimuli that promote arteriosclerotic calcification (15). Athough the contribution of acquired immunity to the progression of CAVD remains to be determined, recent data indicate that an adaptive immune response is likely activated in CAVD as clonally expanded effector-memory T-cell populations are observed in the valve and in the circulation of patients with severe CAS (16) (Fig. 1).

The earliest amorphous calcium phosphate deposition occurs in a stippled pattern on the fibrosal interface with the fibro-fatty expansion of the valve spongiosa (17) and these calcium deposits form readily via epitaxial mineral deposition on a number of nidi, including cholesterol crystals (18), collagen and fragmented elastin fibers (19). Coexpression of collagen and alkaline phosphatase, which in the elastin-rich environment can trigger mineralization, has been demonstrated in CAVD by immunogold electron microscopy (20). Biomineralization also occurs in the absence of alkaline phosphatase, as matrix vesicles contain molecules such as annexin A5, annexin A6, and phosphatidylserine, which readily bind calcium and nucleate mineral deposition (21) while the absence of inhibitors of mineralization such as pyrophosphate, phosphoosteopontin, and fetuin can further promote the deposition of calcium (22). However, following the initiation of mineral deposition, circulating osteoprogenitors (COPs) derived from myeloid cell lineage arrive to the site and play an important role in the subsequent stages of disease response.T These COP cells most likely originate from the bone marrow. The presence of type I collagen (+) CD45 (+) $\mathrm{COP}$ cells in valves has been detected at the fibroproliferative and neovascularization phases of disease, whereas CD45 $(+)$ cells are observed in ossifying and non-ossifying valve segments (23). Circulating myeloid calcifying cells, which are positive for alkaline phosphatase and osteocalcin are elevated in type II diabetes patients, and may contribute to the increased incidence of CAVD in these patients (24).

\section{Inflammation and activation of CAVD pathogenesis}

Inflammation is known to play a significant role in many types of macrovascular calcification, including CAVD (25). A number of the inflammation-associated factors, including tumor necrosis factor, interleukin 1- $\beta$, advanced glycosylation-end products, and oxidized low-density lipoprotein (oxLDL) cholesterol, activate vascular biomineralization and vascular osteogenic signaling processes (26) (Fig. 1). Aggravated fibrocalcific responses have been observed in CAVD in association with increased levels of oxLDL (27). By employing histological studies on human samples and mouse models, it has been demonstrated that reactive oxygen species, specifically hydrogen peroxide, has a pro-osteogenic and pathogenic role in CAVD and that a number of the enzymatic mechanisms that counteract oxidative stress are downregulated in valves during the pathogenesis of CAVD (28). Specifically, hydrogen peroxide has been shown to activate osteogenic Cbfa1/ runt-related transcription factor 2 (Runx2) and Msx2/Wnt signaling pathways to promote mineralization and these pathways are activated in calcifying human aortic valves (28).

\section{Genetics of CAVD}

Advances in genomic technologies have led to the identification of several genes that contribute to the normal development and function of the four heart valves and to the identification of many genetic abnormalities in some of these genes in 
congenital form of CAVD (29). The most common congenital valve anomalies are bicuspid aortic valve (BAV) and mitral valve prolapse (MVP). BAV is estimated to have a prevalence of 1-2\% (30). Normal aortic valve develops until there are three cusps, whereas in BAV disease there is a fusion of two of the leaflets during development, leading to significant morbidity primarily through valve calcification. NOTCH1, a member of the Notch signaling pathway, was one of the first mutated genes identified in BAV. The Jagged/Notch signaling pathway, which plays an important role in bone formation is also central to valve morphogenesis and CAVD. Jagged1 signals from endothelial cells support the Notch1-mediated EMT necessary for cardiac valve morphogenesis during the development of heart (31). Heterozygous loss-of-function NOTCH1 mutations segregate with the disease in families with autosomal dominant BAV (32). Ex vivo, Notch can suppress Runx2 signaling and mineralization (Fig. 2) in VICs (33).

MVP affects 2-3\% of the population and is manifested by systolic displacement of a thickened mitral valve leaflet into the left atrium. This condition is normally observed in adults and often associated with the fibromyxomatous degeneration of the leaflets, valve regurgitation, congestive heart failure, arrhythmias, and infective endocarditis (34). Involvement of transforming growth factor- $\beta$ (TGF- $\beta$ ), which is needed for remodeling and maintenance of mitral valve, in MVP pathogenesis has been suggested (35). TGF- $\beta$, bone morphogenetic proteins, and Wnt, which act via signaling through ALK- and LDL receptor-related protein-receptor complexes to promote bone formation, mineralization, and skeletal homeostasis (Fig. 2), also play an important role in the earliest stages of aortic valve morphogenesis (36). A recent genome-wide association study that included CAVD and mitral annular calcification patients identified a single-nucleotide polymorphism (SNP) in the lipoprotein (a) locus only in CAVD patients (37).

\section{Treatment choices and biomarkers}

As mentioned previously, surgical valve replacement is the widely accepted treatment of choice for AVS, with either mechanical or biological prostheses. Although there are other treatment options, including balloon aortic valvuloplasty or percutaneous valve replacement, they have many limitations. For example, aortic valvuloplasty showed non-trivial complication rates, but moderately high rates of aortic insufficiency with much higher rates of recurrence (38). Percutaneous aortic valve replacement is currently being examined in several studies and appears to be suitable for select groups of patients (39).

Numerous biomarkers have been suggested for following the pathogenesis of aortic valve disease, but not all biomarkers are clinically useful candidates. Presently, asymmetric dimethylarginine, fetuin-A, calcium phosphate product, natriuretic peptides and osteopontin are the most promising candidates. A circulating level of asymmetric dimethylarginine, which is involved in endothelial cell dysfunction, was found to correlate with the extent of AVS (40). Fetuin-A, an inhibitor of soft tissue calcification, also seems to be a good candidate as its serum levels show strong inverse correlation with the extent of valve degeneration and calcification (41). Osteopontin is directly associated with the ectopic calcification process, which occurs during the latter stages of CAVD making this protein a specific biomarker for CAVD (42).

In conclusion, CAVD and other types of VHDs are reaching epidemic status in their prevalence in many developed and developing countries. CAVD ranges from AVSc, i.e., mild thickening of the valve, to AVS, which is severe impairment of the valve motion. Risk factors for acquired valve diseases include age, gender, tobacco use, hypercholesterolemia, hypertension, and type II diabetes mellitus. Diverse cell-dependent mechanisms and signaling pathways orchestrate valve biomineralization with the participation of different cell types including interstitial cells, endothelial cells, cardiac chondrocytes, and COPs. In addition, several genetic mutations that cause congenital valve diseases have been identified along with specific SNPs associated with CAVD. Despite the many advances, there is still a lack of pharmacological treatments for the valve diseases and the most widely accepted approach is surgery. Recent advances in the identification of molecular mechanisms involved in the development and pathogenesis of valvular disease are making a significant impact in our understanding of the heart valve disease.

\section{References}

1. Go AS, Mozaffarian D, Roger VL, Benjamin EJ, Berry JD, Borden WB, Bravata DM, Dai S, Ford ES, Fox CS, et al; American Heart Association Statistics Committee and Stroke Statistics Subcommittee: Heart disease and stroke statistics - 2013 update: a report from the American Heart Association. Circulation 127: e6-e245, 2013

2. Rajamannan NM, Evans FJ, Aikawa E, Grande-Allen KJ, Demer LL, Heistad DD, Simmons CA, Masters KS, Mathieu P, O'Brien KD, et al: Calcific aortic valve disease: not simply a degenerative process: a review and agenda for research from the National Heart and Lung and Blood Institute Aortic Stenosis Working Group. Executive summary: Calcific aortic valve disease-2011 update. Circulation 124: 1783-1791, 2011.

3. d'Arcy JL, Prendergast BD, Chambers JB, Ray SG and Bridgewater B: Valvular heart disease: The next cardiac epidemic. Heart 97: 91-93, 2011.

4. Le Gloan L, Mercier LA, Dore A, Marcotte F, Ibrahim R, Mongeon FP, Asgar A, Miro J, Poirier N and Khairy P: Recent advances in adult congenital heart disease. Circ J 75: 2287-2295, 2011.

5. Katz R, Wong ND, Kronmal R, Takasu J, Shavelle DM Probstfield JL, Bertoni AG, Budoff MJ and O'Brien KD: Features of the metabolic syndrome and diabetes mellitus as predictors of aortic valve calcification in the Multi-Ethnic Study of Atherosclerosis. Circulation 113: 2113-2119, 2006.

6. Itagaki S, Adams DH and Anyanwu AC: Triggers for surgical referral in degenerative mitral valve regurgitation. Circ J 77: 28-34, 2013.

7. Maeda K, Kuratani T, Mizote I, Shimamura K, Takeda Y, Torikai K, Nakatani S, Nanto S and Sawa Y: Early experiences of transcatheter aortic valve replacement in Japan. Circ J 77: 359-362, 2013.

8. Beckmann E, Grau JB, Sainger R, Poggio P and Ferrari G: Insights into the use of biomarkers in calcific aortic valve disease. J Heart Valve Dis 19: 441-452, 2010.

9. Nightingale AK and Horowitz JD: Aortic sclerosis: Not an innocent murmur but a marker of increased cardiovascular risk. Heart 91: 1389-1393, 2005.

10. Tao G, Kotick JD and Lincoln J: Heart valve development, maintenance, and disease: The role of endothelial cells. Curr Top Dev Biol 100: 203-232, 2012.

11. Hinton RB Jr, Lincoln J, Deutsch GH, Osinska H, Manning PB, Benson DW and Yutzey KE: Extracellular matrix remodeling and organization in developing and diseased aortic valves. Circ Res 98: 1431-1438, 2006.

12. Mohler ER III, Gannon F, Reynolds C, Zimmerman R, Keane MG and Kaplan FS: Bone formation and inflammation in cardiac valves. Circulation 103: 1522-1528, 2001. 
13. Boström KI, Jumabay M, Matveyenko A, Nicholas SB and Yao Y: Activation of vascular bone morphogenetic protein signaling in diabetes mellitus. Circ Res 108: 446-457, 2011.

14. Srivatsa SS, Harrity PJ, Maercklein PB, Kleppe L, Veinot J, Edwards WD, Johnson CM and Fitzpatrick LA: Increased cellular expression of matrix proteins that regulate mineralization is associated with calcification of native human and porcine xenograft bioprosthetic heart valves. J Clin Invest 99: 996-1009, 1997.

15. Balachandran K, Alford PW, Wylie-Sears J, Goss JA, Grosberg A, Bischoff J, Aikawa E, Levine RA and Parker KK: Cyclic strain induces dual-mode endothelial-mesenchymal transformation of the cardiac valve. Proc Natl Acad Sci USA 108: 19943-19948, 2011.

16. Winchester R, Wiesendanger M, O'Brien W, Zhang HZ, Maurer MS, Gillam LD, Schwartz A, Marboe C and Stewart AS: Circulating activated and effector memory $\mathrm{T}$ cells are associated with calcification and clonal expansions in bicuspid and tricuspid valves of calcific aortic stenosis. J Immunol 187: 1006-1014, 2011

17. Otto CM, Kuusisto J, Reichenbach DD, Gown AM and O'Brien KD: Characterization of the early lesion of 'degenerative' valvular aortic stenosis. Histological and immunohistochemical studies. Circulation 90: 844-853, 1994.

18. Laird DF, Mucalo MR and Yokogawa Y: Growth of calcium hydroxyapatite (Ca-HAp) on cholesterol and cholestanol crystals from a simulated body fluid: A possible insight into the pathological calcifications associated with atherosclerosis. J Colloid Interface Sci 295: 348-363, 2006.

19. Schoen FJ and Levy RJ: Founder's Award, 25th Annual Meeting of the Society for Biomaterials, perspectives. Providence, RI, April 28-May 2, 1999. Tissue heart valves: Current challenges and future research perspectives. J Biomed Mater Res 47: 439-465, 1999

20. Rajamannan NM, Subramaniam M, Rickard D, Stock SR, Donovan J, Springett M, Orszulak T, Fullerton DA, Tajik AJ, Bonow RO, et al: Human aortic valve calcification is associated with an osteoblast phenotype. Circulation 107: 2181-2184, 2003.

21. Kapustin AN, Davies JD, Reynolds JL, McNair R, Jones GT, Sidibe A, Schurgers LJ, Skepper JN, Proudfoot D, Mayr M, et al: Calcium regulates key components of vascular smooth muscle cell-derived matrix vesicles to enhance mineralization. Circ Res 109: e1-e12, 2011.

22. Jahnen-Dechent W, Heiss A, Schäfer C and Ketteler M: Fetuin-A regulation of calcified matrix metabolism. Circ Res 108: 1494-1509, 2011

23. Egan KP, Kim JH, Mohler ER III and Pignolo RJ: Role for circulating osteogenic precursor cells in aortic valvular disease. Arterioscler Thromb Vasc Biol 31: 2965-2971, 2011.

24. Fadini GP, Albiero M, Menegazzo L, Boscaro E, Vigili de Kreutzenberg S, Agostini C, Cabrelle A, Binotto G, Rattazzi M, Bertacco E, et al: Widespread increase in myeloid calcifying cells contributes to ectopic vascular calcification in type 2 diabetes Circ Res 108: 1112-1121, 2011

25. Wallby L, Janerot-Sjöberg B, Steffensen T and Broqvist M: T lymphocyte infiltration in non-rheumatic aortic stenosis: A comparative descriptive study between tricuspid and bicuspid aortic valves. Heart 88: 348-351, 2002.

26. Towler DA: Molecular and cellular aspects of calcific aortic valve disease. Circ Res 113: 198-208, 2013.
27. Stewart CR, Stuart LM, Wilkinson K, van Gils JM, Deng J, Halle A, Rayner KJ, Boyer L, Zhong R, Frazier WA, et al: CD36 ligands promote sterile inflammation through assembly of a Toll-like receptor 4 and 6 heterodimer. Nat Immunol 11: 155-161, 2010.

28. Miller JD, Chu Y, Brooks RM, Richenbacher WE, Peña-Silva R and Heistad DD: Dysregulation of antioxidant mechanisms contributes to increased oxidative stress in calcific aortic valvular stenosis in humans. J Am Coll Cardiol 52: 843-850, 2008.

29. Lincoln J and Garg V: Etiology of valvular heart disease-genetic and developmental origins. Circ J 78: 1801-1807, 2014.

30. McBride KL and Garg V: Heredity of bicuspid aortic valve: Is family screening indicated? Heart 97: 1193-1195, 2011.

31. Hofmann JJ, Briot A, Enciso J, Zovein AC, Ren S, Zhang ZW, Radtke F, Simons M, Wang Y and Iruela-Arispe ML: Endothelial deletion of murine Jag1 leads to valve calcification and congenital heart defects associated with Alagille syndrome. Development 139: 4449-4460, 2012.

32. Foffa I, Ait Alì L, Panesi P, Mariani M, Festa P, Botto N, Vecoli C and Andreassi MG: Sequencing of NOTCH1, GATA5, TGFBR1 and TGFBR2 genes in familial cases of bicuspid aortic valve. BMC Med Genet 14: 44, 2013.

33. Nus M, MacGrogan D, Martínez-Poveda B, Benito Y, Casanova JC, Fernández-Avilés F, Bermejo J and de la Pompa JL: Diet-induced aortic valve disease in mice haploinsufficient for the Notch pathway effector RBPJK/CSL. Arterioscler Thromb Vasc Biol 31: 1580-1588, 2011.

34. Freed LA, Levy D, Levine RA, Larson MG, Evans JC, Fuller DL, Lehman B and Benjamin EJ: Prevalence and clinical outcome of mitral-valve prolapse. N Engl J Med 341: 1-7, 1999.

35. Lincoln J and Garg V: Etiology of valvular heart disease-genetic and developmental origins. Circ J 78: 1801-1807, 2014.

36. Armstrong EJ and Bischoff J: Heart valve development: Endothelial cell signaling and differentiation. Circ Res 95: 459-470, 2004

37. Thanassoulis G, Campbell CY, Owens DS, Smith JG, Smith AV, Peloso GM, Kerr KF, Pechlivanis S, Budoff MJ, Harris TB, et al; CHARGE Extracoronary Calcium Working Group: Genetic associations with valvular calcification and aortic stenosis. N Engl J Med 368: 503-512, 2013.

38. Balmer C, Beghetti M, Fasnacht M, Friedli B and Arbenz U: Balloon aortic valvoplasty in paediatric patients: Progressive aortic regurgitation is common. Heart 90: 77-81, 2004.

39. Webb JG, Chandavimol M, Thompson CR, Ricci DR, Carere RG, Munt BI, Buller CE, Pasupati S and Lichtenstein S: Percutaneous aortic valve implantation retrograde from the femoral artery. Circulation 113: 842-850, 2006.

40. Vallance P, Leone A, Calver A, Collier J and Moncada S: Accumulation of an endogenous inhibitor of nitric oxide synthesis in chronic renal failure. Lancet 339: 572-575, 1992.

41. Koos R, Brandenburg V, Mahnken AH, Mühlenbruch G, Stanzel S, Günther RW, Floege J, Jahnen-Dechent W, Kelm M and Kühl HP: Association of fetuin-A levels with the progression of aortic valve calcification in non-dialyzed patients. Eur Heart J 30: 2054-2061, 2009.

42. Yu PJ, Skolnick A, Ferrari G, Heretis K, Mignatti P, Pintucci G, Rosenzweig B, Diaz-Cartelle J, Kronzon I, Perk G, et al: Correlation between plasma osteopontin levels and aortic valve calcification: Potential insights into the pathogenesis of aortic valve calcification and stenosis. J Thorac Cardiovasc Surg 138 : 196-199, 2009. 